\title{
ITINERÂNCIAS DE CARMEN TEIXEIRA: VIDA/FORMAÇÃO DA EDUCADORA NA PERSPECTIVA DE GÊNERO
}

\section{CECIILIA MARIA DE ALENCAR MENEZES}

Centro Universitário Estácio da Bahia

RESUMO O interesse investigativo plasmou-se na dimensão reflexiva do procedimento biográfico de Carmen Teixeira, o que nos permitiu tratar, como objeto-processo de pesquisa, os componentes de sua formação pessoal/profissional e a contribuição como educadora/gestora, nos projetos desenvolvidos no âmbito da educação integral e na formação de professoras na Bahia, bem como sua inserção em espaços técnico-administrativos educacionais. O problema da pesquisa configurou-se em questionar: quais as itinerâncias de vida/formação de Carmen Teixeira em sua atividade profissional na educação da Bahia visibilizadas pelas questões de gênero? O objetivo geral foi investigar e reconstruir as itinerâncias de Carmen Teixeira na Bahia pelas relações de gênero. A pesquisa biográfica esteve fundamentada nos referenciais e epistemologias de histórias de vida e de gênero, com abordagem qualitativa e (auto) biográfica, utilizando entrevistas semiestruturadas na coleta de informações, além de materiais biográficos secundários. Concluiu-se que o método biográfico favoreceu um movimento de investigação sobre a dimensão pessoal e o processo de formação, para entender sentimentos, representações e evidências de invisibilidade do seu papel, no desempenho das atividades profissionais, presentes nas relações de gênero, desde a infância à vida adulta, desvelando, assim, as barreiras que the foram interpostas nas relações de gênero, no cenário político-educacional, no espaço público, ocupado predominantemente pelo sexo masculino.

Palavras-chave: História de vida. Gênero. Profissionalidade.

\section{ABSTRACT ITINERANCIES DE CARMEN TEIXEIRA: LIFE / TEACHER TRAINING THE GENDER PERSPECTIVE}

The investigative interest focuses in the reflexive dimension of the biographical procedure about Carmen Teixeira, who allowed to treat the components of her personal/professional training as well as her contribution as educator and manager as object-process of research 
through investigation in the developed projects in the scope of integrated education and teacher's training, in addition to transit in other technical and administrative educational spaces. The research problem set in question: which the itinerancies of life/Carmen's training and professional activity in the education of Bahia through the lens of gender. The overall goal was to investigate and reconstruct the itinerancies of Carmen Teixeira of Bahia through the lens of gender. The biographical research based in the references that consider the epistemologies the histories of life and gender with a qualitative and (auto)biographical approach, using the semi-structured interviews for the collection of information, as well as secondary biographical materials. It was concluded that the biographical method favored a research movement on the personal dimension and training process, to understand feelings, representations and evidence of invisibility of their role in the performance of professional activities present in gender relations since childhood to life adult, revealing thus the barriers that were systematically brought in the relations of gender in the political-educational scenario, in the public space, occupied predominantly by males.

Keywords: History of life. Gender. Professionalism.

El interés investigativo se plasmó en la dimensión reflexiva del procedimiento biográfico de Carmen Teixeira, que posibilitó tratar como un objeto proceso de investigación, los componentes de su formación personal/profesional y la contribución como educador/gerente, en los proyectos desarrollados en el ámbito de la formación integral y formación de los profesores de Bahía, y su inclusión en los espacios técnicos y administrativos educativos. El problema de la investigación se ha configurado en la cuestión: ¿Cuáles las itinerancias de vida/ formación de Carmen Teixeira y actividad profesional en la educación de Bahía visualizadas por las lentes de género? El objetivo general fue el de investigar y reconstruir las itinerancias de Carmen Teixeira en Bahía por las lentes de género. La investigación biográfica se basó en los referenciales y epistemologías de historias de vida y de género, con un enfoque cualitativo y auto biográfico, utilizándose entrevistas semi estructuradas para recopilar informaciones y materiales biográficos secundarios. Se concluyó que el método biográfico favorece un movimiento de investigación sobre la dimensión perso- 
nal y el proceso de formación, para entender sentimientos, representaciones y evidencias de la invisibilidad de su papel en el desempeño de actividades profesionales, presentes en las relaciones de género desde la infancia hasta la vida adulta, revelando así, las barreras a ellas presentadas en las relaciones de género, en el escenario político educativo, en el espacio público, en su mayor parte ocupado por el sexo masculino.

Palabras clave: Historia de vida. Género. Profesionalismo.

\section{Introdução}

O tema deste artigo tem como objeto de pesquisa as itinerâncias de vida de Carmen Spínola Teixeira no contexto onde entretece implicações pessoais, formativas e profissionais, no âmbito da educação, na Bahia, área de reconhecida predominância feminina.

É importante percebermos que a área educacional se constitui notadamente pela presença da mulher no exercício do magistério. $\mathrm{Na}$ atualidade, a profissão docente caracteriza-se como uma profissão de mulher,1 porquanto, passa a ser considerada com menor prestígio e profissionalismo na estrutura de uma sociedade configurada pelo modelo patriarcal2 (HYPÓLITO, 1991 1997). Em contrapartida, quando se trata de reconhecimento profissional e prestígio, no âmbito da educação, são os homens que encontramos em posições de destaque, validados no cenário educacional nacional/ internacional, a exemplo de Anísio Teixeira3 e Paulo Freire.4 Neste cenário, observamos uma

1 Esse fenômeno é tratado como natural e não incorpora a questão do sexo da professora como um elemento significativo para a análise da proletarização do ensino e de suas relações diretas com a feminização do magistério, como discutem, desde a década de 1980, Apple (1987) e Louro (1989).

2 Diz respeito, em linhas gerais, à concentração do poder do homem nas estruturas sociais. Na família, a representação desse poder absoluto concentra-se na figura do pai.

3 Educador e político baiano que empreendeu a reforma da Educação na Bahia e no país, assumindo diferentes cargos públicos, faleceu em 1971.

4 Educador pernambucano que criou o método inovador de alfabetização de adultos, na década de 1960, falecido em 1997. omissão deliberada de registros sobre a contribuição histórica das mulheres, educadoras e gestoras educacionais, que, cotidianamente, se ocupam e se ocuparam da educação de crianças e jovens no nosso país.

Este artigo se coaduna com iniciativas de pesquisa acerca da possibilidade de visibilizar as histórias de vida/formação de educadoras, de reconstruir suas memórias e possíveis contribuições, por tanto tempo, fora dos relatos da história, num processo de silenciamento e invisibilização que se configura pelo fato de não se atribuir relevância alguma ao contar a história das mulheres/educadoras.

Importa-nos também destacar que, além das mulheres, existe "[...] o continente perdido das vidas submersas no esquecimento no qual se anula a massa da humanidade" (PERROT, 2007, p. 16), que tem sua história perpassada e resumida a uma visão reducionista de uma época que se perpetua deliberadamente no imaginário social até os dias atuais. No entanto, sabemos que é sobre as mulheres que o silêncio e a invisibilização recaem.

Seus arquivos particulares eram negligenciados e os arquivos públicos tinham restrições em administrar acervos de pessoas comuns, e mais restrições ainda em relação aos acervos de mulheres, que, "convencidas de sua insignificância", no final da vida destruíam - ou destroem - seus papéis pessoais, promovendo a autodestruição da memória feminina (PERROT, 
2007). Em parte, esses motivos explicam a falta de fontes sobre a vida/formação e a história concreta e singular das mulheres no mundo, com colorido vivo, sem sombras e borrões escurecidos que o tempo insiste em registrar.

Compreendemos que as mulheres/educadoras vivenciaram implicações pessoais e profissionais, em momentos históricos diversos, mas têm em comum o fato de haver pouco ou quase nenhum reconhecimento e/ou evidências de sua existência, tanto na época em que viveram quanto posteriormente. Esse contexto nos leva a pensar em variáveis complexas, fluxos e configurações históricas, registradas na memória individual e coletiva, e legitimadas por transformações sociopolíticas e econômicas das relações do poder masculino.

Inquietações como essas influenciaram as reflexões apresentadas, neste trabalho, quando adotamos uma perspectiva de gênero para nortear nossos estudos e investigações sobre a vida/formação da mulher e educadora baiana Carmen Teixeira, durante, no mínimo, vinte e cinco anos como gestora à frente de uma equipe constituída por homens e um grande contingente de mulheres, orientadas/os por sua concepção de mundo e de educação, na consolidação, implementação curricular e gestão do projeto de educação integral, popular e gratuita, que incluía a formação de professoras, corroborando com o pensamento educacional de seu irmão Anísio Teixeira.

Anísio Teixeira obteve reconhecimento nacional e internacional, como o único mentor intelectual e realizador de tal projeto, enquanto os registros da vinculação de sua irmã a este mesmo projeto se restringiram à citação de seu nome como diretora do Centro Educacional Carneiro Ribeiro (CECR), no período de 1950-1974, em algumas publicações, deixando de ser citada, na maioria delas, inclusive em artigos e teses que abordam a prática pedagógica desenvolvida por Carmen Teixeira e sua equipe no CECR. A partir daí, buscamos investigar suas itinerâncias de vida/formação e suas possiveis contribuições.

Percebemos que, no contexto de vida de Carmen Teixeira, esse "manto de invisibilidade" era o que mais se sobressaía, não havendo registros, impressos ou em meio eletrônico, até março de 2009, que tratassem de sua vida e desempenho profissional como educadora e/ou gestora em instituições das redes particular e pública de ensino. Como evidenciado anteriormente, havia apenas registro de seu nome como diretora, no período de 1950-1971, do CECR, uma publicação e um blog de Bastos (2009) em homenagem ao centenário de seu nascimento. Nesse período, buscamos intensificar as iniciativas de investigar os acervos públicos, realizar levantamento e contato com familiares, colegas, ex-alunos e amigas/os.

Nos estudos de Schienbinger (2001), buscamos subsídios sobre a exclusão e a discriminação das mulheres no espaço acadêmico/profissional e no fazer científico, a partir dos conceitos de Margaret Rossiter ${ }^{5}$ sobre a segregação hierárquica, o fenômeno pelo qual as mulheres são excluídas do topo da carreira científica, de poder e prestígio, e a segregação institucional que diz respeito ao status inferior das mulheres na comunidade científica, pois raramente são convidadas a integrar o corpo docente de conceituadas instituições, ou quando fazem parte demoram a ser promovidas/reconhecidas.

O olhar sensivel a tais estereótipos de gênero nas relações perpassou as observações relativas à reconstrução biográfica, numa dupla perspectiva: da investigação e da formação de mulheres/educadoras, na qualidade de $o b$ -

5 Margaret Rossiter empreendeu esforços na criação de um comitê internacional de mulheres em ciência, tecnologia e medicina, para a sistematização da construção de uma linha de estudos relacionando mulheres e ciências. Os seus estudos (1982) evidenciam a situação das mulheres na ciência, sobretudo os preconceitos e as discriminações sofridos por elas, embora a prática científica se apresente como universalista e assexuada. 
jeto e de sujeito da investigação. Compreendemos, então, que na medida em que o/a pesquisador/a realiza a investigação acerca de uma vida, revisita também suas temporalidades e experiências profissionais, numa dimensão formativa, em profundidade e extensão, em que se aproxima, se identifica e se forma como sujeito, numa lógica de coprodução.

A lógica de coprodução tem uma configuração própria, vinculada às correntes das biografias educativas, manifestando sua singularidade e implicação teórica e política ao pensamento feminista; porquanto apresenta preocupações com objetivos essencialmente emancipatórios, que, segundo Nóvoa (1995), constituem um conjunto de iniciativas em que os profissionais se envolvem, simultaneamente à investigação-formação da pessoa do professor (DOMINICÉ, 2010; JOSSO, 2002), como via de mão dupla, caracterizando-se pelo esforço de globalização e integração, ao relacionar as diferentes perspectivas da investigação, ação e formação.

Por essas lentes, buscamos reconstruir a dimensão reflexiva do procedimento biográfico de Carmen Teixeira, o que nos permitiu tratar os componentes de sua formação pessoal/ profissional e sua contribuição como educadora/gestora, como objeto de pesquisa e como sujeito, mediante investigação de sua participação no cenário político-educacional, no espaço público, predominantemente ocupado pelo sexo masculino, e no caso da família Teixeira, ocupado por Anísio.

A pesquisa requisitou uma verdadeira garimpagem na busca de referências sobre a presença dessa mulher que, dotada de grande capacidade intelectual, mas muito discreta, não articulava o diálogo com a imprensa e políticos da época. ${ }^{6}$ Fica em aberto, se essa atitude seria

6 Essas foram as informações registradas a partir do depoimento oral de uma amiga pessoal e assessora de direção de Carmen Teixeira, no Centro Educacional Carneiro Ribeiro. só um traço predominante de sua personalidade, o indicativo de encontrarmos atualmente tão poucas referências sobre sua vida, ou se perpassa por questões de gênero que envolvem a invisibilidade da mulher, evidenciando a lógica androcêntrica ${ }^{7}$ e excludente presente nos moldes da sociedade patriarcal.

Ao observarmos essa problemática, tivemos como foco principal buscar visibilizar sua atividade profissional na educação da Bahia, bem como as iniciativas pioneiras realizadas no âmbito da formação continuada de professoras, lamentavelmente, ocultada, assim como de tantas outras mulheres/educadoras, incluindo-se, nesse contingente, aquelas que faziam parte do quadro de funcionárias e professoras das escolas: de Aplicação do Centro Regional de Estudos Pedagógicos (CREPE) do Instituto Nacional de Estudos Pedagógicos (INEP) e Escolas Classe I, II, III e IV e do Centro Educacional Carneiro Ribeiro - Escola Parque, em que foi gestora.

Portanto, em reconhecimento pelo seu trabalho, buscamos a reconstrução de sua caminhada através do seguinte problema: quais as itinerâncias de vida/formação de Carmen Teixeira e da atividade profissional na educação da Bahia visibilizadas pelas lentes de gênero?

Focar a biografia de uma mulher parecerá, para muitos, irrelevante, fora de questão, em especial para os que não são sensiveis ou familiarizados com os estudos de gênero e o valor significativo das pesquisas biográficas para os contextos históricos, principalmente os educacionais.

Tratar dessa história à luz do feminismo, observando o patriarcado, a discriminação das mulheres no espaço público, bem como o silenciamento, sem reconhecimento ou valori-

7 Coloca o ser humano do sexo masculino como o centro do universo, como a medida de todas as coisas e no centro das decisões das estruturas políticas de poder, e traduz a convicção de que a condição de masculinidade atribui valor e superioridade ao homem (MORENO, 1999). 
zação no espaço privado, poderá assumir um tom anacrônico ou fora do contexto contemporâneo. No entanto, podemos observar que a inserção profissional e acadêmica, de emancipação, liberdade e realização pessoal das mulheres que são vinculados nas mídias não têm correspondido com a realidade atual.

Então, no intuito de que se concretize essa valorização, dando visibilidade à atuação feminina, no âmbito da educação, o objetivo geral foi investigar as itinerâncias de vida/ formação de Carmen Teixeira e sua atividade profissional de educação na Bahia pelas lentes de gênero; e os objetivos específicos, investigar seu processo de vida/formação como educadora/gestora, bem como evidenciar sua contribuição na implementação curricular do projeto de educação integral e da formação de educadoras na Bahia, analisando, por fim, os fatores que convergiram para o processo de invisibilização de sua atividade profissional no espaço público na Bahia.

\section{Interfaces Teórico-Metodológicas:} sob a ótica das epistemologias feministas na tessitura do método biográfico

As interfaces teórico-metodológicas do processo de investigação ocorreram no intuito de reconstruir a memória individual e coletiva sobre Carmen Teixeira, desvelando as construções sociais de gênero vivenciadas, dentro de parâmetros que norteiam os métodos biográficos, mas também de pressupostos relativos à história oral, na medida em que tivemos conhecimento de apenas um trabalho, sistematizado por Bastos (2009), sobre sua vida.

Buscamos analisar as aproximações entre as concepções acerca das epistemologias feministas, abordagem qualitativa e método biográfico, por reunirem características afins, no sentido de investigar fundamentos que pos- sibilitassem o discernimento necessário aos caminhos conceituais e técnico-operacionais para reconstruir a biografia de Carmen Teixeira.

Essa abordagem epistêmica reconhece a função vital que a emoção exerce no desenvolvimento do conhecimento e da investigação teórica, demonstrando que é preciso conciliar as faculdades da razão e da emoção, abstraídas por nossa cultura. Emoções, observações e avaliações estão ligadas, pois “[...] a observação não é simplesmente um processo passivo de absorver impressões ou registrar estímulos, ao contrário, é uma atividade de seleção e interpretação. 0 que se seleciona e como se interpreta é influenciado pelas atitudes emocionais" (JAGGAR, 1997, p. 167).

Significa dizer que, ao adotar paradigmas epistemológicos feministas, por exemplo, compreendemos sua complexidade e sua representatividade social, onde, cada vez mais, a influência da emoção na percepção está sendo explorada e aquilo que identificamos como emoção é uma abstração conceitual de um complexo processo da atividade que envolve agir, sentir e avaliar, para garantir o rigor científico requerido pela Academia, como evidencia Boaventura (2004).

De acordo com tais pressupostos, a pesquisa aponta para a abordagem qualitativa, por considerarmos a existência de uma relação dinâmica entre o mundo real e o/a pesquisador/a, isto é, uma compreensão mais esclarecedora do objeto de estudo, permitindo, a exemplo dos estudos feministas, "[...] o desenvolvimento de conhecimentos em ciências humanas antes recalcados, por uma ciência que praticou e pratica um sexismo de forma muito mais explícita do que se imagina" (MACEDO, 2006, p. 240).

Nessa perspectiva, a pesquisadora constituiu-se como o instrumento principal, em contato direto com a fonte de dados, entrevistadas/os, o ambiente natural, analisando os 
dados de forma intuitiva, com ênfase na interpretação do significado que cada um/a dos/ as entrevistados/as atribuiu às suas vivências com Carmen Teixeira, apropriando-se, neste estudo, da realidade feminina nos meios educacionais, sensível à condição histórica da mulher em sociedade.

Sendo assim, Nóvoa (20012000) assevera o caráter formativo do método (auto)biográfico, uma vez que se voltar ao passado, acionar a memória ${ }^{8}$ e reconstituir percursos de vida, exercita a reflexão e leva a uma tomada de consciência tanto no plano individual como no coletivo. No entanto, alerta para a diversidade que dá origem a dificuldades, disseminando e legitimando práticas nem sempre dotadas de consistência e de metodologias pouco rigorosas. E chama a atenção de constante vigilância metodológica, no sentido de superar ou evitar equívocos quanto à pesquisa, formação ou pesquisa/formação.

Percorrer esse caminho não se constituiu tarefa das mais fáceis, devido ao processo de invisibilidade que permeia as ações de Carmen Teixeira, para superar os desafios de registrar silenciamentos, preconceitos e discriminações por que passaram/passam as mulheres, neste mundo, predominantemente masculino.

A emergência dos estudos de gênero, a partir de 1960, contou com contribuições recíprocas da explosão do feminismo e das transformações na historiografia, articuladas ao crescimento da antropologia, para elevar as mulheres, da condição de objeto, à de sujeito da História (SOIHET, 2006), apesar de ter sido contestado o seu estatuto teórico, como categoria de análise para interrogar e mudar paradigmas históricos existentes. Scott (1995) foi uma das pioneiras, ao enfatizar a necessidade de supe-

8 Compreendida por Le Goff (2003) como propriedade de conservar determinadas informações, envolve um conjunto de funções psíquicas, nas quais o ser humano pode atualizar impressões ou informações passadas ou assim representadas, podendo evocar traços e problemas da memória histórica e da memória social. ração dos usos descritivos do gênero, para chegar a transformá-los na busca de garantias de emancipação e empoderamento das mulheres.

Para Rago (1995), a importância e a significação dos estudos feministas para a produção do conhecimento, evidenciando o lugar do feminino em nossa cultura, poderão auxiliar na percepção da forma como a sociedade reage às possibilidades das mulheres pensarem com autonomia, como personagens na História e não mais como figurantes ou sombras em torno dos homens, trazendo contribuições significativas.

Por isso, tais estudos sobre a feminização cultural contemporânea, ou seja, o modo pelo qual temas, valores, atitudes e comportamentos femininos foram incorporados na modernidade, fruto das pressões históricas do feminismo, revelou a hierarquização, as relações de poder e a misoginia ${ }^{9}$ presentes na definição das identidades de gênero, destinando, de forma rígida, o espaço público, para os homens, e o privado, para as mulheres.

Como resultante desse universo, temos a dominação masculina identificada nos papéis, práticas e discursos científicos disseminados no cotidiano de modo naturalizado para explicar hierarquias e desigualdades produzidas entre os sexos, frutos da herança do patriarcado (BOURDIEU, 2007). Dessa forma, a hierarquização das relações entre os sexos traça perfis estereotipados e indica comportamentos ambivalentes, emergindo tabus, preconceitos, discursos e representações que legitimam o status de dominante (homens) e dominado (mulheres), havendo, assim, desdobramentos na divisão do trabalho entre mulheres/ homens, onde o homem se localiza no espaço público, com todas as possibilidades de interação, e a mulher fica circunscrita ao espaço privado, limitada às tarefas que esse lócus lhe oferece.

9 Significa aversão às mulheres. 
Este configura um modelo de sociedade patriarcal e androcêntrica, que abrange toda estrutura social que tenha origem no poder do pai e que dedicou à mulher um lugar periférico na sustentação do jogo da dominação (BOURDIEU, 2007. Existindo, assim, um poder invisível que é reproduzido através dos símbolos, os quais são instrumentos, por excelência, de integração social, e, de como o social impregna o sujeito social.

Esse modelo de sociedade não é exclusivo da cultura ocidental, e atribui às mulheres a responsabilidade pela educação dos filhos, colocando em suas mãos o futuro da nação, a ideologia do progresso e a responsabilidade pela perpetuação da fé cristã, dando significado às relações de poder que não são explícitas, mas assumem uma dimensão decisiva da organização de (des)igualdade entre homens e mulheres, evidenciando questões de gênero que caberiam ser analisadas nos contextos históricos.

As construções culturais produzem significados em que o homem normatiza e tem o poder e a mulher submete-se, por ser o sexo frágil que precisa do protetor. Neste contexto, Beauvoir afirma que a submissão e a passividade apresentadas como características essenciais do comportamento da mulher feminina não é um destino biológico, mas “[...] um traço que se desenvolve nela desde pequena [...] na verdade, é um destino que lhe impõem seus educadores e a sociedade" (BEAUVOIR, 1980, p. 315).

Diante desse panorama, para compreender o presente, faz-se necessário pesquisar as itinerâncias e errâncias vividas pelas mulheres, identificar, analisar e conhecer as interações feitas, valendo-nos de procedimentos metodológicos coerentes, que, nessa pesquisa, assume a abordagem biográfica, para proceder a uma análise das vivências de Carmen Teixeira, no sentido de revelar, conhecer sua histori- cidade e dar sentido às experiências vividas, percebendo as relações de gênero, em função dos aspectos biológicos traduzidos em processos discriminatórios, e por receber educação diferenciada, tanto em família, quanto em outras instituições sociais, reforçando as desigualdades impostas, social e culturalmente, no processo de educação da mulher.

As variadas classificações, no uso do método biográfico, inscrevem-se no âmbito de pesquisas socioeducacionais como uma possibilidade de recuperar a singularidade das histórias narradas, a partir da voz dos sujeitos históricos e socioculturalmente situados, garantindo-lhes o seu papel na (re)construção da história individual/coletiva, intermediada por suas vozes, tornando-se, conforme Passeggi (2008), uma ferramenta de renascimento, dos percursos, atitudes, crescimentos, derrotas, posicionamentos, ante as derrotas e ante as vitórias, e as consequências vividas nos espaços privado e público, por conseguinte, constitui-se em um método que privilegia a voz dos sujeitos e escuta também seus silêncios.

Esses aspectos destacam o caráter subjetivo, qualitativo e formativo do método de história de vida. No entanto, precisamos assinalar a diversidade de sentidos e estratégias que podem comprometer a consistência e o rigor das metodologias utilizadas, inerente à "leitura de uma vida", em que a memória se traduz como uma construção social e coletiva (SOUZA, 2003), como espelho das aprendizagens, vivências e representações da inserção do sujeito em seus diferentes grupos sociais.

Nessa pesquisa, os tempos se confundem e tivemos a oportunidade de conhecer e analisar determinadas situações vividas, compreender as influências sociais, econômicas, políticas, religiosas, culturais e educacionais, presentes na processualidade da existência de Carmen Teixeira, no diálogo entre diferentes tempos e espaços, permanências e descontinuidades 
presentes nos diferentes espaços de formação, como também na identidade pessoal e profissional.

O pensamento de que as narrativas biográficas são consideradas fontes imprescindiveis para a constituição e a compreensão da formação de educadoras/es é recente, tornando-se, assim, simultaneamente, um meio de investigação e um instrumento pedagógico. É esta dupla função que justifica a sua utilização no domínio das ciências da educação e da formação (PINEAU, 1987), na medida em que o esforço pessoal de explicitação de uma vida obriga a uma grande implicação e contribui para uma tomada de consciência individual e coletiva.

Os estudos mais recentes sobre formação de professoras/es destacam a pessoa do(a) professor(a), ressaltando a importância da subjetividade e as relações de gênero que perpassam essa formação. De acordo com os estudos de Catani et. al. (2003, p. 28-29),

Para que a escolarização se democratizasse era preciso que o professor custasse pouco: o homem que procura ter reconhecido o investimento na formação, tem consciência de seu preço e se vê com direito à autonomia - procura espaços ainda não desvalorizados pelo feminino. Por outro lado, não se podia exortar as professoras a serem ignorantes, mas se podia dizer que 0 saber não era tudo nem o principal. Exaltar qualidade como abnegação, dedicação, altruísmo e espírito de sacrificio e pagar pouco: não foi por coincidência que este discurso foi dirigido às mulheres [...] quando se trata de aprofundar a vocação feminina ao professorado.

Nesse contexto, a opção metodológica pelo método biográfico e de história de vida requer a articulação necessária de todas as etapas de investigação aos objetivos entre si e ao problema de pesquisa, bem como o alinhamento e a coerência com a seleção dos pressupostos epistemológicos feministas, que irão fundamentar e nortear os itinerários da pesqui- sa como um desafio constante. Corroborando com Becker, coletar

[...] uma história de vida cumpre etapas para garantir que ela abranja tudo o que quer conhecer, que nenhum fato ou acontecimento importante seja desconsiderado, que o que parece real se ajuste a outras evidências disponiveis e que a interpretação do sujeito seja apresentada honestamente. (BECKER, 1999, p. 102)

Por isso, ressaltamos que nos diferentes procedimentos metodológicos a serem construídos e as interpretações que as pessoas fazem de suas próprias experiências para explicar comportamentos, percepções e vivências na reconstituição da história de vida individual e social, ao longo da profissão, são de suma importância para nossa construção, enquanto pesquisador/a.

Constatamos que uma biografia é subjetiva em vários níveis: primeiro, porque através dela o/a pesquisador/a lê a realidade do ponto de vista de um indivíduo historicamente determinado; depois, porque os materiais - em geral autobiográficos - estão sujeitos a inúmeras deformações; se forem descritos, decorrem do fato de ser "um sujeito-objeto que se observa e se reencontra" por meio das interações entre o observador e o observado.

O uso das biografias é reconhecido como fonte legítima de informações, para Ferrarotti (2010, p. 22), mas pondera que isso “[...] não pode confundir-se com a especificidade heurística do método biográfico", uma vez que a mesma "pertence antes à atitude factual dos historiadores sociais que recorrem a fontes orais". Tomar uma biografia como um “exemplo", "caso", ou “ilustração", constitui, segundo este autor, um empobrecimento ainda maior do método, de vez que tal atitude implica uma epistemologia que se contradiz com o pressuposto da subjetividade inerente ao método autobiográfico, comprometendo também os objetivos da pesquisa, que deve 
buscar contar a história da pessoa tal como ela a experienciou.

De acordo com Finger ( 2010, p. 127), “[...] o método biográfico surge como resultado de considerações epistemológicas e teóricas e na perspectiva de pôr em prática processos de tomada de consciência, ou seja, processos que são considerados formadores para os adultos". O termo método biográfico valoriza a compreensão do que se desenrola no interior da pessoa, sobretudo em relação aos sentimentos, vivências e a experiências que tiveram lugar na sua história de vida.

Sabemos que percorrer essas itinerâncias se constituiu em uma tarefa delicada e singular, por isso, contamos com as/os teóricas/os que pudessem contribuir com nossos estudos, persistindo nos objetivos definidos na pesquisa, de forma articulada à construção das interfaces teórico-metodológicas; realizamos a coleta de informações e as entrevistas, e, de novo voltamos aos escritos das/os teóricas/os no diálogo com as/os entrevistadas/os, o que se apresentou como etapa prioritária da dinâmica do método biográfico fidedigno ao movimento constitutivo do ser, seguindo as trilhas das pesquisadoras de gênero.

O caminho a ser trilhado durante o processo de investigação, sob o ponto de vista analítico-reflexivo, assumiu o desafio de contar a história de Carmen Teixeira, evidenciando o processo de invisibilidade do seu papel de mulher e educadora, o que perpassa as relações de gênero em sua existência, para reconstituir aspectos de sua vida pessoal e sua carreira, a partir do contexto histórico-cultural. Assim, ocorreu de acordo com o que nos diz Bogdan e Biklen (1994) e Dominicé (2010), quando enfatizamos o papel da família, das instituições de ensino, acontecimentos marcantes e outras pessoas com influências relevantes e comprovadas na sua formação, definindo a sua história e sua ótica de vida.
A relevância de um estudo dessa natureza está na contribuição que poderá trazer à compreensão das relações de gênero e educação, no âmbito nacional, especialmente na sociedade baiana, pela força do seu exemplo em alicerçar e manter uma obra educacional consistente, comprometida com a educação dos mais pobres e a educação de professoras, o que poderá influenciar e contribuir, ainda, para a compreensão do papel da mulher/educadora nos dias atuais.

Esse caminho, portanto, foi construído pelas narrativas das pessoas entrevistadas, que conheceram e/ou conviveram com Carmen Teixeira, no âmbito das relações familiares e institucionais/sociais, a partir dos sentidos que por nós foram interpretados, do que pudemos fazer emergir destes discursos, bem como do material biográfico secundário: documentos de época, livros, revistas, jornais e outros produzidos por ela (cartas, pareceres, entre outros). Foram depoimentos situados de parentes, amigas/os, colegas de trabalho, ex-alunas/ os, professoras/es, funcionárias/os radicados em diferentes localidades (Salvador, Caetité, Rio de Janeiro, Brasília).

As pessoas entrevistadas possuíam formação diversificada e, por isso, desenvolvem atividades profissionais as mais diversas, mas, em sua maioria, tem por afinidade ou vinculação, atividades relativas à educação. Foram mulheres e homens de diferentes origens, idades, escolaridade, classes sociais e profissões (adultos, idosas/os, aposentadas/os, políticos, historiadores, educadoras/es, porteiros, motoristas, domésticas, funcionárias/os públicas/os), que se relacionaram de alguma forma com D. Carmen ou Carmita, como era chamada pelos membros da família.

Essa tessitura foi construída a partir de cada experiência que é multirreferencial, porquanto os fios foram entrelaçados numa teia complexa, de características semelhantes, nos 
mais variados contextos em que estão presentes na experiência vivida/lembrada, em diferentes situações, assumindo, dessa maneira, diferentes sentidos.

O conceito de experiência como mais representativa de uma posição do que de uma essência, teve por inspiração a perspectiva de Scott (1995, p. 42) que afirma ser a “[...] experiência um evento linguístico (não acontece fora dos significados). Já que o discurso é, por definição, compartilhado, a experiência é coletiva assim como individual. Experiência é uma história do sujeito. A linguagem é o local onde a história é encenada". Assim, pudemos concluir que as experiências constituem as histórias das itinerâncias vividas e foram também constituídas por elas, mas não de forma aleatória, conforme se encontraram disponibilizadas nos tempos e espaços da linguagem, do social, cultural e histórico.

Tomamos o método biográfico como aporte metodológico, buscando, nesses tempos e espaços mencionados, coletar informações sobre a vinculação pessoal/profissional com os entrevistados (colegas de profissão, ex-alunas/os, familiares e amigas/os), bem como o registro de levantamento de imagens e documentos pessoais e de época, para reconstruir espaços pessoais e profissionais de Carmen Teixeira.

No caso desta pesquisa, fizemos entrevistas em profundidade, e utilizamos, com entrevistados idosos, roteiros de entrevistas semiestruturadas e apresentação de fotos, servindo de "pistas" para facilitar a organização do pensamento, minimizando as exigências da memória. Esses foram procedimentos afins aos pressupostos epistemológicos adotados, os quais admitem emoções, observações e avaliações, de forma interligada.

Por isso, foram considerados, também, as expressões, desejos e sentimentos, que emergiram por parte das/os entrevistadas/os, na interação com a entrevistadora, durante a execução destes procedimentos de coleta de informações, ainda que existisse algum direcionamento de nossa parte. Essa atitude se distancia de um modelo de entrevista perfeitamente neutra. Para Bogdan e Biklen (1994, p. 36) “[...] as boas entrevistas caracterizam-se pelo fato de os sujeitos estarem à vontade e falarem livremente sobre seus pontos de vista", buscando entender os sentimentos e representações das/os entrevistadas/os, a partir da escuta de suas histórias de vida e suas interfaces relacionais com Carmen Teixeira, (re)contadas durante a construção do conhecimento, com apoio na empatia que estabelecemos para saber sentir o universo afetivo, imaginário e cognitivo, desses atores sociais e, então, poder compreender de dentro suas atitudes, comportamentos e sistema de ideias, de valores e símbolos, nas vivências formativas, experiências e vínculos gerados nessas relações com Carmen Teixeira.

$\mathrm{Na}$ tessitura desses caminhos, essa história de vida emergiu com o alcance da visão que aprendemos a olhar por lentes de gênero, neste momento de nossa própria itinerância, quando visibilizamos, também, os entraves em nossa formação de mulher/educadora e os processos de discriminação vividos, nos quais identificamos questões sutis de manutenção do poder masculino nas relações de gênero. No entanto, buscamos o equilíbrio para evitar que o entrelace comprometesse o distanciamento necessário à consecução dos objetivos da pesquisa: reconstruir a vida de Carmen Teixeira e dar visibilidade a suas contribuições educacionais.

\section{Considerações finais}

Tratar da história de uma vida não significa seguir uma cronologia linear, mas buscar descrever as itinerâncias, desde a infância até a fase adulta, que se faz de idas e vindas, parti- 
das e chegadas, construções e desconstruções, avanços e recuos, em função dos diversos fatores implicados a uma existência. E, assim, evidenciar as variadas influências que tiveram família e escola, como espaços prioritários onde se educa e se constrói principalmente, a mulher, que, ao passar por muitas formas de acomodação e resistência, corresponde, por fim, às expectativas estereotipadas de papéis sexuais e torna-se educadora.

Evidenciamos que o método biográfico possibilitou entender os sentimentos, representações e evidências de invisibilidade do papel desta mulher, presentes nas relações de gênero, negados na perspectiva de neutralidade do modelo positivista de ciência moderna. E no cenário educacional baiano, muito nos diz respeito à riqueza, beleza e significação denotadas no seu legado profissional e familiar, reconhecidamente por testemunhos de afeto, admiração profissional e amizade.

Ademais, vale ressaltar que, em sua itinerância, tanto pela forma como pela abrangência que ocupou esse espaço público, observamos uma dinâmica que envolvia autonomia, autoridade e empreendedorismo, os quais não

\section{Referências}

APPLE, Michael. Relações de classe de gênero e modificações no processo de trabalho docente. Cadernos de Pesquisa, São Paulo, n. 60. p. 3-14, fev. 1987.

BASTOS, Zélia. Associação de Senhoras de Caridade de Caetité 1919/ 2010. Salvador: Egba, 2010.

BASTOS, Zélia. Carmem Spínola Teixeira: uma biobibliográfica. Salvador: EDUFBA, 2009.

BEAUVOIR, Simone. 0 segundo sexo: a experiência vivida. Tradução de Sérgio Milliet. 10. ed. Rio de Janeiro: Nova Fronteira, 1980.

BECKER, Howard S. Método de pesquisa em ciências sociais. 4. ed. São Paulo: Hucitec, 1999. se encaixavam, como atributos femininos, no espaço educacional.

O exercício de (re)olhar essa experiência de vida, na tentativa de retomar o fio condutor que possibilita rever o cenário educacional e a formação de professoras, bem como a construção social de ser mulher e ser homem, e filtrar dessas experiências vividas, construções e desconstruções socioculturais, uma vez que ficou perceptível para nós que o brilho de Carmen Teixeira foi ofuscado pela figura de Anísio Teixeira, o que pode evidenciar as questões sexistas envolvendo o lugar do masculino e do feminino, por demais impregnadas no seu ser, no espaço formativo familiar em que cresceu, reverenciando os feitos do irmão e admirando-o.

Daí a importância do uso do método de história de vida e dos estudos de gênero, para, cada vez mais, tornar visivel aos olhos daquelas/es que ainda não possuem essas "lentes", que ampliem suas percepções para as desigualdades, silenciamentos e assimetrias que discriminam as diferenças de toda ordem, entre os seres humanos, fazendo jus à obra dessas mulheres invisibilizadas, como foi o caso de Carmen Teixeira.

BOAVENTURA, Edivaldo M. Metodologia da pesquisa: monografia, dissertação, tese. São Paulo: Atlas, 2004.

BOGDAN, Robert; BIKLEN, Sari. Investigação qualitativa em educação: uma introdução à teoria e aos métodos. Tradução de Maria João Alvarez, Sara Bahia dos Santos e Telmo Mourinho Baptista. Portugal: Porto, 1994.

BOURDIEU Pierre. A dominação masculina. Tradução de Maria Helena Kühner. 5. ed. Rio de Janeiro: Bertrand Brasil, 2007.

CATANI, Denice Bárbara et. al. Memória e Autobiografia na Pesquisa Educacional e na Formação. In: CATANI, Denice Bárbara; BUENO, Belmira Oliveira; 
SOUSA, Cyntia Pereira de; SOUZA, M. Cecília C. C.(Orgs.) Docência, memória e gênero: estudos sobre formação. São Paulo: Escrituras Editora, 2003, p. 13-48.

CATANI, Denice Bárbara. Práticas de formação e ofício docente. In. BUENO Belmira Oliveira; CATANI, Denice Barbara; SOUSA, Cynthia Pereira. (Orgs.). A vida e o ofício dos professores: formação contínua, autobiografia e pesquisa em colaboração. São Paulo: Escrituras, 1998. p. 21-29.

DELORY-MOMBERGER, Christine. Biografia e educação: figuras do indivíduo-projeto. Tradução de Maria da Conceição Passeggi, João Gomes da Silva Neto e Luis Passeggi. Natal, Rio Grande do Norte: EDUFRN; São Paulo: Paulus, 2008.

DOMINICÉ, Pierre. A biografia educativa: instrumento de investigação para a educação de adultos. In: NÓVOA, Antônio; FINGER, Matthias. (Orgs.). 0 método autobiográfico e a formação. Natal: EDUFRN; São Paulo: Paulus, 2010. p. 143-153. (Pesquisa (auto) biográfica. Clássicos das Histórias de vida).

DOMINICÉ, Pierre. O que a vida thes ensinou. In: NÓVOA, Antônio; FINGER, Matthias (Orgs.). 0 método (auto)biográfico e a formação. Natal, Rio Grande do Norte: EDUFRN; São Paulo: Paulus, 2010. p. 189-222. (Pesquisa (auto) biográfica. Clássicos das histórias de vida).

FERRAROTTI, Franco. Sobre a autonomia do método biográfico. In: NÓVOA, Antônio; FINGER, Matthias. 0 método autobiográfico e a formação. (Orgs.). Natal: EDUFRN; São Paulo: Paulus, 2010. p. 31-57. (Pesquisa (auto) biográfica. Clássicos das Histórias de vida).

FINGER, Matthias. As implicações socioepistemológicas do método biográfico. In: NÓVOA, Antônio; FINGER, Matthias. (Orgs.). 0 método autobiográfico e a formação. Natal: EDUFRN; São Paulo: Paulus, 2010. p.119-128. (Pesquisa (auto) biográfica. Clássicos das Histórias de vida).

HYPÓLITO, Álvaro L. Moreira. Trabalho docente, classe social e relações de gênero. São Paulo: Papirus, 1997.

JAGGAR, Alisson. Amor e conhecimento: a emoção na epistemologia feminista. In: JAGGAR, Alisson; BORDO, Susan R. Gênero, corpo e conhecimento.
Tradução de Britta Lemos de Freitas. Rio de Janeiro: Record; Rosa dos Tempos, 1997. p. 157-183.

JOSSO, Marie-Christine. Experiências de vida e formação. Lisboa, EDUCA, 2002.

LE GOFF, Jacques. História e memória. Tradução de Bernardo Leitão. 5. ed. Campinas, SP: Editora da UNICAMP, 2003.

LOURO, Guacira. Magistério de 1o grau: um trabalho de mulher. Educação e Realidade, Porto Alegre, n. 2, p. 53-67, jul./dez. 1989.

MACEDO, Roberto Sidnei. Etnopesquisa crítica tnopesquisa-formação; o fudante da educação. Brasília, DF: Líber Livro, 2006.

MORENO, Montserrat. Como se ensina a ser menina: o sexismo na escola. Coordenação Ulisses Ferreira de Araújo Trad. Ana Venite Furzado. São Paulo: Universidade Estadual de Campinas, 1999. (Educação em pauta: escola e democracia). NÓVOA, Antônio. Professores: imagens do futuro presente. Lisboa: Educa, 2009.

PERROT, Michelle. Os excluídos da história: operários, mulheres e prisioneiros Tradução de Denise Bottmann. Rio de Janeiro: Paz e Terra, 1988.

PASSEGGI, Maria da Conceição; BARBOSA, Tatyana Mabel Nobre. (Orgs.). Memórias, memoriais: pesquisa e formação docente. Natal: EDUFRN; São Paulo: Paulus, 2008.

PERROT, Michelle. Minha história das mulheres. Trad. Ângela M. S. Correia. São Paulo: Contexto, 2007.

PINEAU, Gaston. A autoformação no decurso da vida: entre a hetéro e a ecoformação. In: NÓVOA, Antônio; FINGER, Matthias. (Orgs.). 0 método autobiográfico e a formação. Natal: EDUFRN; São Paulo: Paulus, 2010. p. 97-118 (Pesquisa (auto) biográfica. Clássicos das Histórias de vida).

PINEAU, Gaston. Temps et Contretemps. Montreal: Èdition Saint-Martin, 1987.

NÓVOA, Antônio. Os professores e as histórias de suas vidas. In: NÓVOA, Antônio (Org.) Vidas de Professores. Portugal: Porto, 2000. p.11-30.

NÓVOA, Antonio. Profissão Professor. Porto: Porto, 1995. 
POIRIER, Jean; CLAPIER-VALLADON, Simone; RAYBAUT, Paul. Histórias de vida: teoria e prática. Paris: Celta, 1999.

RAGO, Margareth. Feminizar é preciso ou por uma cultura filógena. Rio de Janeiro: Paz e Terra, 1995.

ROSSITER, Margaret W. Women Scientists in America. Struggles and Strategies to 1940. Conference of Women Historians Prize Paperback. ISBN: 9780801825095, August, 1984.

SCHIENBINGER, Londa. 0 feminismo mudou a ciência? Tradução de Raul Fiker. Bauru, SP: EDUSC, 2001. (Coleção Mulher).

SCOTT, Joan. W. Gênero: uma categoria útil para análise histórica. Tradução de Cristina R. Dabat e Maria Betânia Ávila. Recife: SOS Corpo, 1995.
SOIHET, Rachel. História das mulheres e relações de gênero: algumas reflexões. In: III JORNADA DE ESTUDOS DA ANTIGUIDADE, 2006, Rio de Janeiro. Anais... III Jornada de Estudos da Antiguidade. Rio de Janeiro: NAPE/UERJ; Fábrica de Livro/SENAI, 2006. p. 90-99.

SOUZA, Elizeu Clementino de. História de vida e formação de professores: um olhar sobre a singularidade das narrativas (auto) biográficas. In: MACEDO, Roberto Sidnei. (Org.). Currículo e docência: tensões contemporâneas, interfaces pós-formais. Salvador: UNEB, 2003. p. 35-56.

VIEIRA, Ricardo. Histórias de vida e interculturalidade. Lisboa: Afrontamento, 1999.

Recebido em: 11.01.2016. Aprovado em: 25.03.2016.

Cecília Maria de Alencar Menezes é Pedagoga, Doutora em Educação - UFBA/FACED; Mestre em Educação e Contemporaneidade UNEB/PEC. Atualmente, Coordenadora de Gestão Educacional na Secretaria de Educação do Estado da Bahia - SEC/BA. Professora do Instituto Superior de Educação Ocidemnte - ISEO e do Centro Universitário Estácio da Bahia - Estácio FIB. e-mail: cecimenezes@yahoo.com.br.

Alameda Praia de Suape, 51 QD. J Lote 31 Stella Maris, Salvador - Bahia. CEP 41.600-030 